\title{
Potential predictors of psychological distress and well-being in medical students: a cross-sectional pilot study
}

This article was published in the following Dove Press journal:

Advances in Medical Education and Practice

2 March 2016

Number of times this article has been viewed

\author{
Miles Bore' \\ Brian Kelly ${ }^{2}$ \\ Balakrishnan Nair ${ }^{2}$ \\ 'School of Psychology, ${ }^{2}$ School of \\ Medicine and Public Health, University \\ of Newcastle, Newcastle, NSW, \\ Australia
}

Purpose: Research has consistently found that the proportion of medical students who experience high levels of psychological distress is significantly greater than that found in the general population. The aim of our research was to assess the levels of psychological distress more extensively than has been done before, and to determine likely predictors of distress and well-being.

Subjects and methods: In 2013, students from an Australian undergraduate medical school $(n=127)$ completed a questionnaire that recorded general demographics, hours per week spent studying, in paid work, volunteer work, and physical exercise; past and current physical and mental health, social support, substance use, measures of psychological distress (Kessler Psychological Distress Scale, depression, anxiety, stress, burnout); and personality traits.

Results: Females were found to have higher levels of psychological distress than males. However, in regression analysis, the effect of sex was reduced to nonsignificance when other variables were included as predictors of psychological distress. The most consistent significant predictors of our 20 indicators of psychological distress were social support and the personality traits of emotional resilience and self-control.

Conclusion: The findings suggest that emotional resilience skills training embedded into the medical school curriculum could reduce psychological distress among medical students.

Keywords: medical student, well-being, psychological distress, personality

\section{Introduction}

The findings of research into the mental health of university students generally, and medical students in particular, are of concern. For example, $30 \%$ of a large sample of students from an Australian university were found to be depressed, be anxious, have an eating disorder, or engage in harmful drinking. ${ }^{1}$ High-to-very high levels of psychological distress in medical students were found in Sweden, ${ }^{2}$ Norway, ${ }^{3}$ Australia, ${ }^{4,5}$ Spain, ${ }^{6}$ and the US and Canada in a review of 40 articles. $^{7}$

Poor mental health is also seen after graduation from medical schools, and there has been a long-standing call for the development of strategies to improve the health of doctors. ${ }^{8}$ This has included a focus on reducing the psychological stress of medical training and medical practice. ${ }^{9}$ In a longitudinal study, from graduation year to fourth-year residency, a $17 \%$ prevalence of mental health problems was found. The best predictors were previous stress in medical school and prior mental health problems. ${ }^{10}$ Studies to date indicate that doctors experience higher rates of mental health problems, such as depression and substance use, than the general population. ${ }^{11}$ Nevertheless, doctors are less likely to seek health care for such problems when it is needed. ${ }^{10,12}$ The most severe
Correspondence: Miles Bore School of Psychology, University of Newcastle, University Drive, Callaghan, Newcastle, NSW 2308, Australia

Tel $+6 \mid 249216585$

Fax +61249216980

Email Miles.Bore@newcastle.edu.au 
and tragic of the consequences of these unaddressed mental health needs is that doctors have higher rates of suicide than the general population. ${ }^{11}$

In Australia, a national mental health survey of doctors and medical students ${ }^{13}$ found higher rates of psychological distress and suicide attempts compared to Australian population norms and to other Australian professionals. This was particularly pronounced for young doctors and female doctors. Very high levels of psychological distress, as indicated by a score of 30 or more on the Kessler Psychological Distress $\mathrm{Scale}^{14}$ (K10), were found in $9.2 \%$ of medical students compared to $3.1 \%$ found in the general population and $4.4 \%$ of interns. A greater proportion of female medical students (10.4\%) had high levels of psychological distress than male medical students $(7.1 \%)$.

It would seem clear that more work is needed to develop effective prevention and early intervention programs that address the stress of medical training and the transition to early years of clinical practice. ${ }^{15}$ Early medical training provides a critical opportunity to address barriers to appropriate attention to health care needs among doctors. One study found that it was not the personal problems but medical training issues that were the stressors among students. Introduction of increased student feedback, guidance, and the provision of adequate learning resources were suggested as stress-reduction strategies. ${ }^{16}$ In another study, second-year medical students who were given an elective in "mind-body skills" had reduced anxiety scores compared to the baseline. ${ }^{17}$

While awareness is growing that intervention in the form of mental health skill building is needed within the medical school curriculum, research based on a more comprehensive psychologically based model of protective and vulnerability factors is required. Such research has the potential to show more clearly where intervention might be aimed. To study this, we developed a model similar to one proposed by Dunn et $\mathrm{al}^{18}$ of protective vs vulnerability factors to psychological distress as the foundation of our research. The pilot study is reported here.

Each student brings into the medical education context (and any other context) their endogenous trait, eg, their sex and their personality traits. Exogenous variables are those that make up the individual's medical education context, and might include such factors as hours per week required for study (including lectures, tutorials, and reading), access to health services, living arrangements, relationship status, level of social support, year of study within the medical program, paid and/or volunteer work, physical exercise undertaken, leisure time, and financial concerns. A combination of endogenous and exogenous variables should have some power to predict individual differences in the level of psychological distress experienced in the medical education context. This in turn could suggest what to target in order to manage and minimize psychological distress.

A consistent finding in the literature is that of sex differences on measures of psychological distress, with females typically reporting greater distress that males. ${ }^{1,13}$ It is for this reason that we included sex as an endogenous variable in our model of protective vs vulnerability factors.

The literature on personality and psychological distress is substantial, but the typical finding is that emotional stability (vs neuroticism) and self-control (vs disorderliness) are negatively related to psychological distress. ${ }^{19,20}$ For the research reported here, we used a three-trait "resilient well-being" model developed from previous work in medical student selection ${ }^{21}$ and empirical research with medical and other allied health students. ${ }^{22}$ The model consists of the traits of involvement, emotional resilience, and self-control (see Figure 1).

A measure of psychological distress that has been used in medical student research is the K10, as just noted. Student burnout has also been examined, ${ }^{2,23}$ and could be considered an indicator of distress level in response to the demands of medical education and each individual's ability to selfmanage in that context. ${ }^{24}$ Other distress indicators might be use of health services, substance use, days off due to mental health, levels of stress, anxiety and depression, self-esteem, and general satisfaction with life.

The aim of this study was to investigate the psychological health and well-being among a representative sample of medical students enrolled in an Australian undergraduate medical program. We sought to assess more extensively the levels of psychological distress than had been done before, and to examine likely predictors of distress and well-being. The expectations were that a significant proportion of students would be experiencing psychological distress, and that endogenous and exogenous variables would significantly predict psychological distress and related indicators.

\section{Subjects and methods Participants}

The sample consisted of 127 students (from a total of 709 students; response rate $18 \%$ ) enrolled in a 5-year medical program in 2013 at an Australian university. Recruitment targeted years 1,3 , and 5, although participation was open to all students. Participant numbers in each year were 33 , six, 36 , four, and 46 , respectively (two unrecorded). There were 32 males, 93 females 


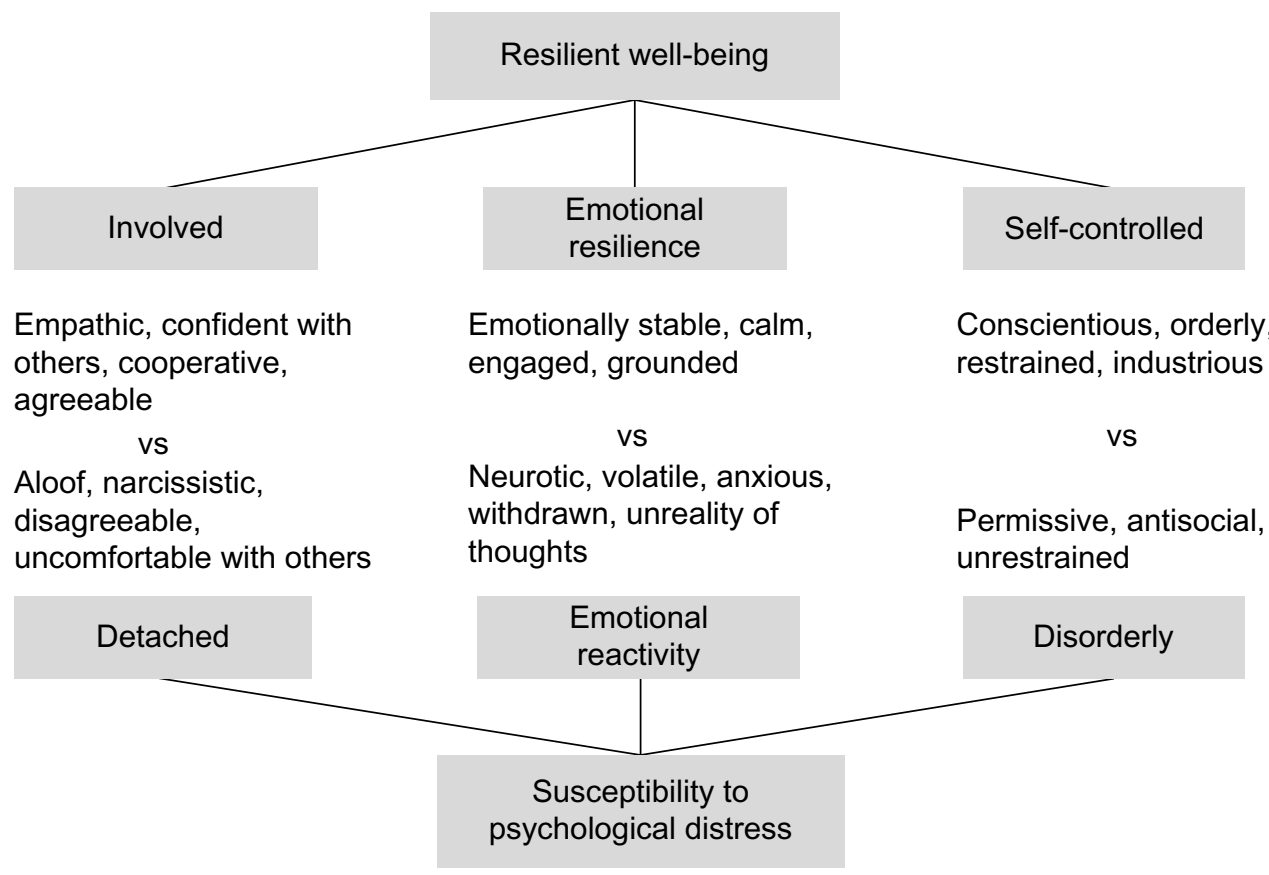

Figure I Three personality traits of the health professional resilience model. Note: Based on the findings reported in Munro et al. ${ }^{22}$

(two unrecorded), and the mean age was 23 (standard deviation 5.6, median 22, range 17-49) years. All enrolled were full-time students, and 28 had tertiary qualifications.

\section{Instruments}

The questionnaire battery consisted of nine sections.

\section{General demographics}

Information on sex, age, accommodation during semester and other times (with parents, friends, partner, alone, other), relationships (married, partnered, single [in relationship], single [no current relationship], separated, or divorced), year of current degree, intended area of medical practice, and previous tertiary qualifications was gathered.

\section{Work and study}

Average weekly hours of study (lectures, tutorials, reading, studying), hours of paid work during and outside semester, hours of volunteer work during and outside semester, and concern about day-to-day finances (not concerned, somewhat, very) were assessed.

\section{Health}

Questions on physical health over the past 5 years, current physical health, mental health over the past 5 years, and current mental health were all answered on a 5-point scale of very poor to excellent. A further nine questions, based on a modified version of a survey of student experiences of support services, ${ }^{25}$ asked about awareness of health-support services at the university.

\section{Exercise and leisure}

Hours of exercise and other physical activities in a typical week, how satisfying (5-point scale, not satisfying to highly satisfying) these are, other leisure/hobbies, and how satisfying (5-point scale) these are were recorded.

\section{Social support}

Participants completed the Duke Social Support Index (DSSI), ${ }^{26}$ which comprises eleven questions, such as "How many times did you talk to someone - friends, relatives or others - on the phone in the last week (either they called you or you called them)?" with eight response options (0-7 or more) and "Do you feel useful to your family and friends (ie, people important to you)?" with answer options of "hardly ever", "some of the time", and "most of the time". Three scores are derived from the DSSI: social interaction with others over the past week, satisfaction with relationships with others, and overall social support.

\section{Substance use}

The ten-item Alcohol Use Disorders Identification Test ${ }^{27}$ and ten-item Cannabis Use Disorders Identification Test ${ }^{28}$ were used. 


\section{Psychological distress}

The 21-item short form of the Depression, Anxiety, and Stress Scale (DASS) ${ }^{29}$ with items such as "In the past week, I felt scared without any good reason" (4-point scale, "did not apply to me at all" to "applied to me very much, or most of the time". Included in the battery was the ten-item K10, ${ }^{14}$ with such questions as "In the last 4 weeks, about how often did you feel depressed?", answered using five response options ("none of the time" to "all of the time"). The K10 also includes four additional questions that ask about time away from work or study due to the feelings reported in questions $1-10$ of the scale. Participants also completed the Satisfaction with Life Scale, ${ }^{30}$ which consists of five items, such as "I am satisfied with my life" answered on a 7-point scale ("strongly disagree" to "strongly agree"), and the ten-item Rosenberg Self-Esteem Scale, ${ }^{31}$ eg, "I wish I could have more respect for myself", reverse-scored, with a 4-point response scale of "strongly agree" to "strongly disagree".

\section{Student burnout}

The Maslach and Jackson Burnout Inventory ${ }^{32}$ was adapted for a tertiary-level student context by the researchers using the same subscale structure as the original. Emotional exhaustion was measured using nine items, eg, "I feel I can't cope anymore", eight items for lack of personal accomplishment, eg, "I feel like I've lost my purpose in my studies", and six items for depersonalization eg, "I worry that my studies are hardening me emotionally", with all items answered using a 5-point scale from "strongly disagree" to "strongly agree".

\section{Personality}

Participants completed the 100-item Health Professional Values Survey (HPVS), ${ }^{33}$ which measures three personality traits that form a model of psychological resilience. The traits are involvement with others (high scores indicating empathy and confidence in dealing with others) vs detachment from others (low scores indicating aloofness and narcissistic behavior), emotional resilience (high scores indicating emotional stability and low scores indicating neuroticism), and self-control (orderly, conscientious, restrained) vs disorderliness (messy, impulsive, permissive). High scores on all three traits indicate psychological resilience, while low scores indicate susceptibility to psychological distress. The items (eg, "I don't waste my time on people who have caused their own problems") are answered using a 4-point scale: "never true about you" to "always true about you".

\section{Procedure}

The research proposal was approved by the University of Newcastle Human Research Ethics Committee. Participants were recruited by email, in which the research was described and an invitation given to complete the questionnaire battery, which was made available online from a secure server internal to the university. Participants could log in and complete the battery at a time and location of their choice. The time taken to complete the battery was not recorded, but was estimated to take approximately 40 minutes from pilot testing. In order to recognize the time and effort involved, participants who completed the battery had a one in ten chance of receiving a AU\$20 shopping voucher. Data were collected over the period of semester 1 (March to May 2013). No identifying information was recorded with the data. Participants were advised that completion of the questionnaire would be taken as consent. Data were then downloaded, and descriptive and statistical analyses performed. Missing-item data were replaced with the midrange of the item's response scale. The analyses utilized two-tailed $t$-tests, correlation, and regression techniques. The level of statistical significance used in all instances was $P<0.05$, two-tailed.

\section{Results}

Responses to questions concerning general demographics, study, work, leisure activities, and health were collated and

Table I Accommodation, relationships, study, work, health, finances, and intended specialization

\begin{tabular}{lllll}
\hline Accommodation & During semester, \% (n) & Outside semester, \% (n) & Relationship status & \% (n) \\
\hline With friends & $50.4(64)$ & $11.0(14)$ & Single, no current relationship & $48.0(6 \mathrm{I})$ \\
Partner & $12.6(16)$ & $9.4(12)$ & Single, in steady relationship & 25.2 (32) \\
Parents or relatives & $10.2(13)$ & $68.5(87)$ & Partnered & Married \\
Alone & $9.4(12)$ & $3.9(5)$ & Separated or divorced & $3.9(5)$ \\
University college & $8.7(11)$ & 0 & No response & 1.6 (2) \\
Shared house & $7.1(9)$ & $1.6(2)$ & & $3.1(4)$ \\
Other/no response & $1.6(2)$ & $5.5(7)$ & \\
\hline
\end{tabular}


Table I (Continued)

\begin{tabular}{|c|c|c|c|c|c|}
\hline Work and health & $\mathbf{n}$ & Mean hours & SD & Median & Range \\
\hline Study per week & 122 & 38 & 17.7 & 40 & $3-120$ \\
\hline Paid work in semester & 43 & 8 & 6.3 & 8 & $1-35$ \\
\hline Paid work outside semester & 58 & 23.2 & I5.I & 20 & $1-60$ \\
\hline Volunteer work in semester & 39 & 3.8 & 2.5 & 4 & $0.2-10$ \\
\hline Volunteer work outside semester & 36 & 5 & 4.1 & 4 & $0.1-15$ \\
\hline Exercise/physical activity in semester & 126 & 4.5 & 3.1 & 4 & $0-15$ \\
\hline Exercise/physical activity outside semester & 120 & 5.7 & 4.2 & 5 & $0-20$ \\
\hline Satisfied with exercise/physical activities & 119 & 4.1 & 1.0 & 4 & $\mathrm{I}-5$ \\
\hline \multirow[t]{2}{*}{ Satisfied with other leisure activities } & 100 & 4.4 & 0.8 & 5 & $\mathrm{I}-5$ \\
\hline & & Mean rating & SD & Median & Range \\
\hline Physical health, past 5 years & 126 & 3.9 & 0.7 & 4 & $\mathrm{I}-5$ \\
\hline Mental health, past 5 years & 127 & 3.5 & 1.0 & 4 & $1-5$ \\
\hline Current physical health & 127 & 4.0 & 0.7 & 4 & $1-5$ \\
\hline Current mental health & 127 & 3.6 & 0.9 & 4 & $\mathrm{I}-5$ \\
\hline Intended specialization & $\%(n)$ & \multicolumn{3}{|c|}{ Use of health services } & Yes, \% (n) \\
\hline Not sure yet & $40.9(52)$ & \multicolumn{3}{|c|}{ Aware of University Health support } & $81(103)$ \\
\hline General practice & $15.7(20)$ & \multicolumn{3}{|c|}{ Services promoted adequately } & $38(49)$ \\
\hline Surgery & $13.4(17)$ & \multicolumn{3}{|c|}{ Know someone who has used service } & $46(59)$ \\
\hline Psychiatry & $4.7(6)$ & \multicolumn{3}{|c|}{ Were they satisfied? } & $63(37)$ \\
\hline Pediatrics & $4.7(6)$ & \multicolumn{3}{|c|}{ Have you used health services? } & $33(42)$ \\
\hline Physician/emergency medicine & $3.9(5)$ & \multicolumn{3}{|c|}{ Were you satisfied? } & $71(30)$ \\
\hline Obstetrics & $3.1(4)$ & \multicolumn{3}{|c|}{ Comfortable seeking university services } & $67(85)$ \\
\hline Anesthetics & $3.1(4)$ & \multicolumn{3}{|c|}{ Comfortable seeking services outside university } & $65(82)$ \\
\hline Forensics & $0.8(I)$ & \multicolumn{3}{|c|}{ Do you have a GP you can see? } & $63(80)$ \\
\hline Hematology & $0.8(1)$ & & & & \\
\hline Oncology & $0.8(1)$ & \multicolumn{3}{|c|}{ Finances } & n (\%) \\
\hline Ophthalmology & $0.8(1)$ & \multicolumn{3}{|c|}{ Concerned about finances: no } & $25(19)$ \\
\hline Pathology & $0.8(1)$ & \multicolumn{3}{|c|}{ Somewhat } & $79(62)$ \\
\hline No response & $6.3(8)$ & \multicolumn{3}{|c|}{ Very } & $23(18)$ \\
\hline
\end{tabular}

Abbreviation: SD, standard deviation.

examined to provide a profile of the student sample (see Table 1). During the semester, $50.4 \%$ of students lived with friends, while outside semester time $68.5 \%$ lived with parents or other relatives. The majority of students were single ( $73.2 \%$ ), with $48 \%$ of these having no current relationship. Responses to the question of how many hours of lectures, tutorials, reading, and studying students did in a typical semester week ranged widely from 3 hours (one respondent) to 120 hours (two respondents), with the median being 40 hours per week. Of the 127 students in the sample, $43(33.8 \%)$ undertook an average of 8 hours a week paid work during semester. An average of 3.8 hours per week was spent on volunteer work during the semester by 39 (30.1\%) students. A further 4.5 hours were taken up with exercise or other physical activity, and most found this satisfying and enjoyable. A large proportion of students (79\%) were somewhat concerned about their finances, while $23 \%$ of these were very concerned. General practice was the most popular intended specialization, although $40.9 \%$ of students responded "not sure yet".
As is also shown in Table 1, physical and mental health over the past 5 years and currently were rated on average (on a 5-point scale) between 3 (minor problems) and 4 (generally good). However, mental health over the past 5 years was rated significantly lower $(P<0.05)$ than physical health over the past 5 years $(t=3.77, P<0.001)$, and current mental health was rated significantly lower than current physical health $(t=3.19$, $P=0.002)$. The majority of the sample ( $81 \%)$ were aware of the university general practice and student-counseling health services, with $33 \%$ having used the services; $63 \%$ had a general practitioner they could see as needed.

Measures of psychological distress and personality were scored, the $\alpha$-reliabilities examined, and the means and standard deviations calculated for males and females (see Table 2). All measures showed acceptable-to-high internal reliability, with the exception of the social interaction subscale of the DSSI. With regard to sex differences, compared to males, females had significantly higher mean scores for depression, anxiety, and stress as measured by the DASS, higher psychological distress scores as indicated by the K10, 
Table 2 Mean and standard deviation for males and females

\begin{tabular}{|c|c|c|c|c|c|c|c|c|}
\hline \multirow[t]{2}{*}{ Scale } & \multirow[t]{2}{*}{ Variable } & \multicolumn{3}{|c|}{ Males } & \multicolumn{4}{|c|}{ Females } \\
\hline & & $\mathbf{n}$ & Mean & SD & $\mathbf{n}$ & Mean & SD & $\alpha$ \\
\hline \multirow[t]{3}{*}{ DSSI } & Social interaction & 32 & 7.7 & 1.5 & 91 & 7.3 & 1.4 & 0.22 \\
\hline & Satisfaction & 32 & 18.7 & 2.1 & 91 & 18.5 & 2.1 & 0.70 \\
\hline & Social support, total & 32 & 26.4 & 2.7 & 91 & 25.9 & 2.7 & 0.43 \\
\hline \multirow[t]{3}{*}{ DASS } & Depression & 32 & 7.6 & 5.8 & 92 & $11.2 *$ & 10.4 & 0.88 \\
\hline & Anxiety & 32 & 4.3 & 3.7 & 92 & $8.5^{*}$ & 9.4 & 0.86 \\
\hline & Stress & 32 & $1 \mathrm{I} .7$ & 6.5 & 92 & $14.7 *$ & 9.6 & 0.84 \\
\hline $\mathrm{KIO}$ & Psychological distress & 31 & 16.8 & 4.3 & 91 & $20.6^{*}$ & 7.2 & 0.88 \\
\hline AUDIT & Alcohol use, total & 31 & $6.7^{*}$ & 5.0 & 91 & 4.5 & 4.3 & 0.75 \\
\hline CUDIT & Cannabis use, last 6 months & 7 & - & - & 5 & - & - & - \\
\hline RSES & Self-esteem & 30 & $30.6^{*}$ & 3.6 & 91 & 28.4 & 5.8 & 0.87 \\
\hline SWLS & Satisfaction with life & 30 & 22.7 & 7.3 & 91 & 23.3 & 7.6 & 0.91 \\
\hline \multirow[t]{4}{*}{ Burnout } & Emotional exhaustion & 27 & 26.3 & 6.1 & 82 & 28.0 & 7.3 & 0.87 \\
\hline & Lack of personal accomplishment & 27 & 21.9 & 5.7 & 82 & 22.4 & 6.5 & 0.86 \\
\hline & Depersonalization & 27 & 11.6 & 3.7 & 82 & 12.8 & 4.7 & 0.79 \\
\hline & Burnout total & 27 & 59.8 & 12.5 & 82 & 63.2 & 15.6 & 0.92 \\
\hline \multirow[t]{3}{*}{ HPVS } & Involved vs detached & 25 & 127.8 & 11.0 & 82 & $134.9 *$ & 13.3 & 0.85 \\
\hline & Emotional resilience & 25 & 71.3 & 7.9 & 82 & 68.2 & 12.9 & 0.91 \\
\hline & Self-control & 25 & 70.3 & 9.5 & 82 & $75.3 *$ & 8.9 & 0.86 \\
\hline
\end{tabular}

Note: *Differences between sex mean scores is significant at $P<0.05$.

Abbreviations: SD, standard deviation; DSSI, Duke Social Support Index; DASS, Depression, Anxiety, and Stress Scale; KI0, Kessler Psychological Distress Scale; AUDIT, Alcohol Use Disorders Identification Test; CUDIT, Cannabis Use Disorders Identification Test; RSES, Rosenberg Self-Esteem Scale; SWLS, Satisfaction with Life Scale; HPVS, Health Professional Values Survey.

and lower self-esteem. Males reported significantly higher rates of alcohol consumption than females. In response to the Cannabis Use Disorders Identification Test, seven (22\%) males and five (5.4\%) females reported using cannabis over the past 6 months (given this small number of users, no frequency-of-use analysis was conducted). For the HPVS measure of personality, females were significantly more involved with others and had higher self-control compared to males. No sex differences were observed for social support, satisfaction with life, burnout, or emotional resilience.

The sample's mean scores on the DASS were compared to the published norms. ${ }^{29}$ The male mean depression, anxiety, and stress scores were no different to the male norms. However, females were significantly more depressed, anxious, and stressed compared to the female norms (all $P<0.001$ ). The DASS norms also provide severity ratings by sex, with scores distributed from "normal" to "extreme severity". As shown in Table 3, 19\% of the males in the sample were in the moderate range of depression scores and $13 \%$ in the moderate range for anxiety and for stress. The proportion of females in the severe and extremely severe range was much higher for depression, anxiety, and stress. K10 psychological distress scores were compared to the national mental health survey of doctors and medical students ${ }^{13}$ and the 2007 National Survey of Mental Health and Wellbeing ${ }^{34}$ findings. The distribution of males' K10 scores was the same as found in the general adult population, and compared to medical student and allstudent norms, the scores showed less psychological distress. The proportion of females in the high and very high ranges was similar to the medical student and all-student norms, but greater than the all-adult norms.

In order to produce manageable and meaningful regression models, we selected eleven variables as predictors based on an initial examination of the correlation matrix of all variables. Sex and the personality variables of involvement, emotional resilience, and self-control were selected as endogenous predictors. Exogenous predictor variables were: year of study $(1,3$, or 5$)$; hours per week of study (including lecture and tutorial attendance), paid work during semester, volunteer work during semester, and exercise or other physical activity; concern about finances; and level of social support as measured by the DSSI. The variable of hours per week of study was considered a predictor variable, as it included lecture and tutorial attendance, as well as reading and studying, and so provided a surrogate measure of the demands of a medical degree. Hours per week studying was also examined as an outcome variable on the basis that the time devoted to study was an indicator of engagement with one's degree.

The other outcome variables examined were the use of the university health services, alcohol use, cannabis use, K10 psychological distress score, DASS scores, burnout scores (total score and the three subscores), self-esteem, and satis- 
Table 3 Sample DASS and KIO scores compared to norm distributions

\begin{tabular}{|c|c|c|c|c|c|c|c|c|}
\hline \multirow[t]{2}{*}{ DASS } & \multicolumn{4}{|c|}{ Male, \% (n) } & \multicolumn{4}{|c|}{ Female, \% (n) } \\
\hline & \multicolumn{2}{|c|}{ Depression } & Anxiety & Stress & \multicolumn{2}{|l|}{ Depression } & Anxiety & Stress \\
\hline Normal & \multicolumn{2}{|c|}{$72(23)$} & $75(24)$ & $75(24)$ & \multicolumn{2}{|l|}{$54(50)$} & $60(55)$ & $61(56)$ \\
\hline Mild & \multicolumn{2}{|l|}{$6(2)$} & $13(4)$ & $9(3)$ & \multicolumn{2}{|l|}{$14(13)$} & $7(6)$ & $9(8)$ \\
\hline Moderate & \multicolumn{2}{|l|}{$19(6)$} & $13(4)$ & $13(4)$ & \multicolumn{2}{|l|}{$12(11)$} & $12(11)$ & $13(12)$ \\
\hline Severe & \multicolumn{2}{|l|}{$3(1)$} & 0 & $3(1)$ & \multicolumn{2}{|l|}{$7(7)$} & $7(6)$ & $13(12)$ \\
\hline Extremely severe & 0 & & 0 & 0 & $12(11)$ & & $15(14)$ & $4(4)$ \\
\hline \multirow[t]{2}{*}{ KIO } & \multirow{2}{*}{$\begin{array}{l}\text { Sample } \\
\% \text { (n) }\end{array}$} & \multicolumn{3}{|c|}{ Male norms, \% } & \multirow{2}{*}{$\begin{array}{l}\text { Sample } \\
\% \text { (n) }\end{array}$} & \multicolumn{3}{|c|}{ Female norms, \% } \\
\hline & & $\begin{array}{l}\text { Medical } \\
\text { students }\end{array}$ & All students & All adults & & $\begin{array}{l}\text { Medical } \\
\text { students }\end{array}$ & All students & $\begin{array}{l}\text { All } \\
\text { adults }\end{array}$ \\
\hline Low (10-19) & 77 (24) & 51 & 63 & 75 & $48(44)$ & 41 & 57 & 67 \\
\hline Moderate (20-24) & $19(6)$ & 31 & 32 & 19 & $24(22)$ & 34 & 31 & 23 \\
\hline High (25-29) & $3(1)$ & 11 & 4 & 4 & $13(12)$ & 16 & 8 & 7 \\
\hline Very high $(30-50)$ & 0 & 7 & I & 2 & $14(13)$ & 10 & 5 & 4 \\
\hline
\end{tabular}

Notes: KI0 norms for medical students from Beyond Blue. ${ }^{13}$ "All students" and "all adults" norms from the National Survey of Mental Health and Wellbeing (2007) report, given in Beyond Blue. ${ }^{13}$

Abbreviations: DASS, Depression, Anxiety, and Stress Scale; K I0, Kessler Psychological Distress Scale.

faction with life. Included as outcome variables were two of the four additional K10 questions: days unable to work, study, or manage your day in the last 4 weeks due to these feelings (feelings being responses to items $1-10$ of the K10), and days you cut down on what you did due to these feelings. The four questions that asked participants to rate their physical health and mental health over the past 5 years and currently were also included as outcome variables.

The procedure for each multiple linear regression run was to correlate the eleven predictor variables against an outcome variable. Only variables that were found to be significantly related to the outcome were then included in the regression model for that outcome. As shown in the first row of Table 4, study hours per week was significantly and positively correlated with self-control $(r=0.24)$ and year of study $(r=0.19)$ : participants who spent more time studying tended to have higher self-control and were more likely to be in a higher year. Study hours per week was then regressed against selfcontrol and year of study. Standardized $\beta$-weights are shown in Table 4 (to the right of the correlation coefficients), where the predictor variable reached significance in the regression model. For study hours per week, the standardized $\beta$-weight for self-control was 0.21 and for year of study was 0.25 . In this model, these two variables accounted for $10.4 \%$ of the variance in study hours per week. All regression models shown in Table 4 were statistically significant.

The results given in Table 4 show that higher use of the university health services was related to being female, having lower emotional resilience, being in a higher year of study, and having greater financial concerns. Conversely, lower use of the health services was related to being male, being more emotionally resilient, being in an earlier year of study, and having lower financial concerns. However, emotional resilience was found to be the only significant unique predictor.

Lower self-control and higher hours in paid work per week were significant predictors of alcohol use (Alcohol Use Disorders Identification Test scores) and cannabis use in the last 6 months. Eight of the predictors were related to psychological distress, with three being significant negative predictors (low emotional resilience, self-control, and study hours per week), the model in total accounting for $57.2 \%$ of the variance in psychological distress.

Of note was that while sex was significantly related to 12 of the 20 outcome variables, it was not found to be a significant unique predictor in any of the regression models. Emotional resilience was a significant predictor in 16 of the 20 models, self-control in seven models, and social support in five models. The burnout regression model had the largest number of significant unique predictors: high burnout scores were predicted by low involvement, low emotional resilience, low exercise hours per week, and low social support.

\section{Discussion}

Our expectation that a significant proportion of students would be experiencing psychological distress was partly supported. Males in our sample were generally no more distressed than the general population, although 13\%-19\% of males scored in the moderate range on both the DASS and the K10. Females were significantly more distressed than males, and more distressed when compared to other students and the general population. 


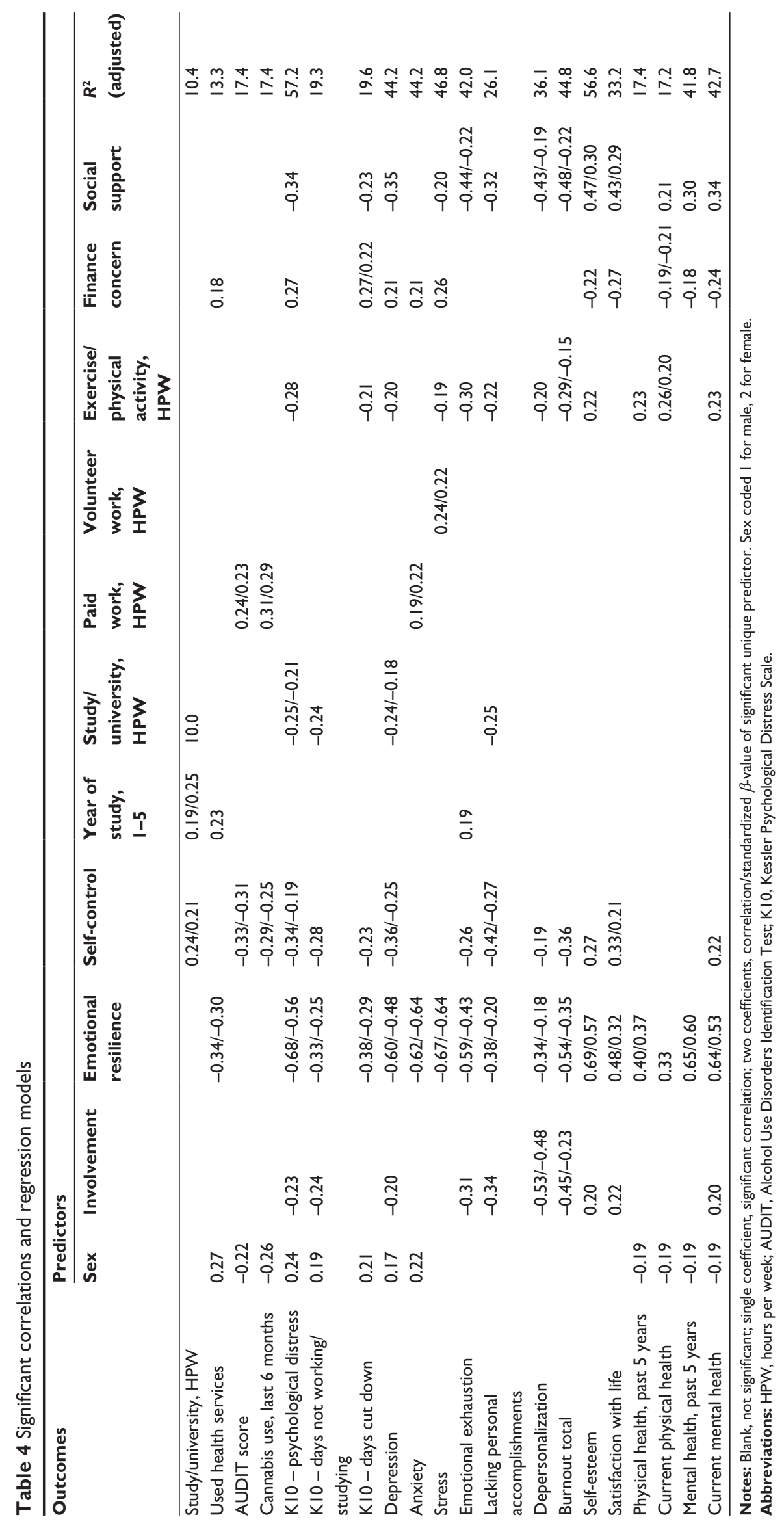


The exogenous variables, which indicate each individual's medical education context, of accommodation, relationship status, and intended specialization were not significantly related to any of the psychological distress or well-being measures, although there was a trend toward those living alone to be more psychologically distressed. However, being in a higher year of study, spending more hours studying and attending university, and having more hours of paid work and volunteer work were associated with higher psychological distress. Greater financial concern was also associated with greater distress, as has been found by others. ${ }^{1}$ Exercise hours per week and social support were associated with lower psychological distress.

Significant sex differences were found with a number of variables, and to a large extent replicated the differences reported by many others. Of note, however, was that while females were significantly more involved and self-controlled, they were no different to males in their emotional resilience scores: females typically scored lower than males on the personality trait of emotional stability. No sex differences were observed for burnout scores, nor on self-esteem or satisfaction with life scores.

As noted, the relatively small number of males in the sample means these findings need the support of replication with a large and more balanced sample. Why males were more reluctant to participate than females is not clear. The smaller proportion of males that we found reporting high psychological distress compared to the norm might suggest that distressed males were less willing to participate than distressed females. We note that the proportion of male respondents in the Beyond Blue national survey ${ }^{13}$ of medical students and the Said et al $^{1}$ university student study $(37.4 \%$ and $34 \%$, respectively) reflected to some degree the smaller proportion $(25 \%)$ of male students willing to participate in our study.

Although sex correlated significantly with 12 of our 20 outcome variables, it was not found to be a unique significant predictor in any of the regression models. This is a finding of some importance, as it suggests that while sex is related to various indicators of psychological distress, the effect becomes nonsignificant when other more strongly related variables, such as personality traits and social support, are considered. Interpretations of the findings regarding social support need to be made with some caution, given the low $\alpha$-reliability found for social interaction. It could be that a more reliable measure of social support would have produced stronger relationships with the outcome variables and perhaps have been a significant predictor of more of the indicators of distress.

With regard to personality, low self-control was predictive of alcohol use, cannabis use, K10 scores, depression, lack of personal accomplishment, and low satisfaction with life. However, the strongest predictor of 14 of the 20 indicators of psychological distress measured was the personality trait of emotional resilience. In earlier unpublished research, ${ }^{35}$ with a sample of 427 Australian undergraduate students, a correlation of -0.86 between emotional resilience (as measured by the HPVS) and neuroticism (vs emotional stability, as measured by the NEO PI-R [Neuroticism-ExtroversionOpenness Personality Inventory - revised] $)^{36}$ was found strongly, suggesting that both scales are measuring the same personality trait. In the present study, the trait of emotionality was a significant predictor of use of the health services, K10 scores, days not at work/study, or cut down on work/ study due to psychological distress, depression, anxiety and stress scores, burnout, past physical health, past and current mental health, self-esteem, and satisfaction with life. Given the strength of the relationships between emotional resilience and these outcome variables, which ranged from -0.33 to -0.69 with significant regression standardized $\beta$-weights ranging from -0.18 to -0.64 , it would seem clear that this is an important and relevant trait in the context of medical student well-being.

The findings overall suggest that greater social support and high emotional resilience are key factors in minimizing and managing psychological distress and enhancing well-being. Put another way, medical students with low social support and low emotional resilience are at risk of experiencing high levels of psychological distress, including depression, anxiety, stress, and burnout. While there has been some research into embedding general resilience training into university courses, ${ }^{37}$ our findings suggest a more targeted approach could help avoid the development of psychological distress. Self-knowledge of one's level of social support and emotional resilience and training in strategies (such as physical exercise, as found here) and skills that improve the management of one's emotions could be worthwhile incorporating into the medical school curriculum.

A limitation of this study is the small sample size and particularly the small proportion of males in the sample, and further research is clearly required. The study was crosssectional, and so lacks the predictive ability of a longitudinal study. However, the strength of the relationships found here does suggest the potential for the findings to be replicated. Further consideration could be given to possible other trait 
and situation variables relevant to the medical education environment. For example, homosexual and bisexual university students have been found to report greater psychological distress than heterosexual students, ${ }^{1}$ and perhaps the inclusion of this factor would have been informative in our study. Additionally, we found that approximately a third of our sample did not feel comfortable in seeking help from health services within and outside the university, and further research into the reasons for this could be undertaken.

\section{Conclusion}

The level of psychological distress in our sample of female medical students is consistent with that found in previous research. Male medical students reported lower psychological distress. The personality traits of emotional resilience and to a lesser extent self-control, together with level of social support, were found to be significant predictors of a wide range of indicators of psychological distress and wellbeing. While confirmatory research with larger numbers is needed, we suggest that the current data support a need for emotional resilience-skills training to be embedded into medical school curricula. This could reduce the experience of psychological distress for medical students and perhaps provide resilience skills that can be utilized in their future practice of medicine.

\section{Disclosure}

$\mathrm{MB}$ is one of the authors of the Personal Qualities Assessment battery of tests, and receives a royalty payment when the PQA is used commercially. He did not receive any payment for the use of the HPVS in this study. BK and BN report no conflicts of interest in this work. The research was funded by the authors. Preliminary findings were presented as an oral presentation at the Australian Conference on Personality and Individual Differences, Griffith University, Brisbane, Australia, November 22-23, 2013.

\section{References}

1. Said D, Kypri K, Bowman J. Risk factors for mental disorder among university students in Australia: findings from a web-based crosssectional survey. Soc Psychiatry Psychiatr Epidemiol. 2013;48: 935-944.

2. Dahlin ME, Runeson E. Burnout and psychiatric morbidity among medical students entering clinical training: a three year prospective questionnaire and interview-based study. BMC Med Educ. 2007;7:6.

3. Midtgaard M, Ekeberg Ø, Vaglum P, Tyssen R. Mental health treatment needs for medical students: a national longitudinal study. Eur Psychiatry. 2008;23:505-511.

4. Leahy CM, Peterson RF, Wilson IG, Newbury JW, Tonkin AL, Turnbull D. Distress levels and self-reported treatment rate for medicine, law, psychology and mechanical engineering tertiary students: crosssectional study. Aust N Z J Psychiatry. 2010;44:608-615.
5. Bore M, Ashley-Brown G, Gallagher E, Powis D. Personality and the prevalence of psychiatric symptoms in medicine and psychology students. In: Boag S, editor. Personality Down Under: Perspectives from Australia. New York: Nova Science Publishers Inc; 2008:158-165.

6. Sender R, Salamero M, Vallés A, Valdés M. Psychological variables for identifying susceptibility to mental disorders in medical students at the University of Barcelona. Med Educ Online. 2004;9:9.

7. Dyrbye LN, Thomas MR, Shanafelt TD. Systematic review of depression, anxiety, and other indicators of psychological distress among U.S. and Canadian medical students. Acad Med. 2006;81:354-373.

8. Firth-Cozens J. Interventions to improve physicians' well-being and patient care. Soc Sci Med. 2001;52:215-222.

9. Goebert D, Thompson D, Takeshita J, et al. Depressive symptoms in medical students and residents: a multischool study. Acad Med. 2009;84:236-241.

10. Tyssen R, Vaglum P, Grønvold N, Ekeberg O. Factors in medical school that predict postgraduate mental health problems in need of treatment. A nationwide and longitudinal study. Med Educ. 2001;35:110-120.

11. Center C, Davis M, Detre T, et al. Confronting depression and suicide in physicians: a consensus statement. JAMA. 2003;289:3161-3166.

12. Dunn LB, Green Hammond KA, Roberts LW. Delaying care, avoiding stigma: residents' attitudes toward obtaining personal health care. Acad Med. 2009;84:242-250.

13. Beyond Blue. National Mental Health Survey of Doctors and Medical Students. Melbourne: Beyond Blue; 2013. Available from: http://www. beyondblue.org.au/docs/default-source/research-project-files/bl1132report---nmhdmss-full-report_web. Accessed January 30, 2015.

14. Kessler RC, Andrews G, Colpe LJ, et al. Short screening scales to monitor population prevalences and trends in non-specific psychological distress. Psychol Med. 2002;32:959-976.

15. Firth-Cozens J. Doctors, their wellbeing, and their stress: it's time to be proactive about stress - and prevent it. BMJ. 2003;326:670-671.

16. Moffat KJ, McConnachie A, Ross S, Morrison JM. First year medical student stress and coping in a problem-based learning medical curriculum. Med Educ. 2004;38:482-491.

17. Finkelstein C, Brownstein A, Scott C, Lan YL. Anxiety and stress reduction in medical education: an intervention. Med Educ. 2007;41:258-264.

18. Dunn LB, Iglewicz A, Moutier C. A conceptual model of medical student well-being: promoting resilience and preventing burnout. Acad Psychiatry. 2008;32:44-53.

19. Ozer DJ, Benet-Martínez V. Personality and the prediction of consequential outcomes. Annu Rev Psychol. 2006;57:401-421.

20. Tangney J, Baumeister RF, Boone AL. High self-control predicts good adjustment, less pathology, better grades and interpersonal success. J Pers. 2004;72:271-324.

21. Bore M, Munro D, Powis DA. A comprehensive model for the selection of medical students. Med Teach. 2009;31:1066-1072.

22. Munro D, Bore M, Powis D. Personality determinants of success in medical school and beyond: "steady, sane and nice". In: Boag S, editor. Personality Down Under: Perspectives from Australia. New York: Nova Science Publishers Inc; 2008:103-111.

23. Dyrbye LN, West CP, Satele D, et al. Burnout among U.S. medical students, residents, and early career physicians relative to the general U.S. population. Acad Med. 2014:89:443-451.

24. Williams D, Tricomi G, Gupta J, Janise A. Efficacy of burnout interventions in the medical education pipeline. Acad Psychiatry. 2015;39:47-54.

25. Hillis JM, Perry WR, Carroll EY, Hibble BA, Davies MJ, Yousef J. Painting the picture: Australasian medical student views on wellbeing teaching and support services. Med J Aust. 2010;192:188-190.

26. Koenig HG, Westlund RE, George LK, Hughes DC, Blazer DG, Hybels C. Abbreviating the Duke Social Support Index for use in chronically ill elderly individuals. Psychosomatics. 1993;34:61-69.

27. Babor TF, Higgins-Biddle JC, Saunders JB, Monterio MG. AUDIT-The Alcohol Use Disorders Identification Test: Guidelines for Use in Primary Care. Geneva: World Health Organization; 2001. Available from: http:// apps.who.int/iris/bitstream/10665/67205/1/WHO_MSD_MSB_01.6a. pdf. Accessed January 19, 2016. 
28. Adamson SJ, Sellman JD. A prototype screening instrument for cannabis use disorder: the Cannabis Use Disorders Identification Test (CUDIT) in an alcohol-dependent clinical sample. Drug Alcohol Rev. 2003;22:309-315.

29. Lovibond SH, Lovibond PF. Manual for the Depression Anxiety Stress Scales. 2nd ed. Sydney: Psychology Foundation of Australia; 1995.

30. Pavot W, Diener E. Review of the Satisfaction with Life Scale. Psychol Assess. 1993;5:164-172.

31. Rosenberg M. Society and the Adolescent Self-Image. Princeton (NJ): Princeton University Press; 1965.

32. Maslach C, Jackson SE. The measurement of experienced burnout. J Occup Behav. 1981;2:99-113.
33. Bore M, Munro D, Powis D. Health Professional Values Survey. Newcastle, Australia: University of Newcastle; 2012.

34. Australian Bureau of Statistics. ABS Health Surveys, Australia, 2007-2008. Canberra: Australian Bureau of Statistics; 2012.

35. Apostolatos P, Bore M. "Out there": personality and personality disorder predictors in an undergraduate student population. Poster presented at: Australian Conference on Personality and Individual Differences; December 2-3, 2010; Wollongong, Australia.

36. Costa PT, McCrae RR. Revised NEO Personality Inventory (NEO PI-R). Lutz (FL): Psychological Assessment Resources; 1992.

37. Stallman HM. Embedding resilience within the tertiary curriculum: a feasibility study. High Educ Res Dev. 2011;30:121-133.

\section{Publish your work in this journal}

Advances in Medical Education and Practice is an international, peerreviewed, open access journal that aims to present and publish research on Medical Education covering medical, dental, nursing and allied health care professional education. The journal covers undergraduate education, postgraduate training and continuing medical education including emerging trends and innovative models linking education, research, and health care services. The manuscript management system is completely online and includes a very quick and fair peer-review system. Visit http://www.dovepress.com/testimonials.php to read real quotes from published authors.

Submit your manuscript here: http://www.dovepress.com/advances-in-medical-education-and-practice-journal 